\title{
As possibilidades de uso do software de análise
} qualitativa nvivo"

\author{
Valesca Daiana Both Ames ${ }^{97}$
}

\section{RESUMO}

Este artigo pretende discutir as potencialidades e limites do uso do software de análise qualitativa Nvivo a partir da exposição da possibilidade de aplicação do referido software ao estudo do processo de construção social do Aeromóvel em Porto Alegre/RS. No artigo são abordados os principais recursos oferecidos pelo software, e como eles funcionam. Para tanto, apresentamos algumas etapas de organização e análise dos dados, seguindo nossa pesquisa exemplo. Este exercício torna-se importante na medida em que permite uma maior familiaridade com o uso desta ferramenta auxiliar de pesquisa qualitativa.

Palavras chave: NVivo. Pesquisa qualitativa. Análise de dados. Construção social.

\section{ABSTRACT}

The article discusses the potentialities and limitations of the use of qualitative analysis software Nvivo from exposure of the possibility of application of the software to study Aeromóvel's social construction process in Porto Alegre/RS. In this paper is covered the main features offered by the software, and how they work. Therefore, we present some steps of organizing and analyzing data, following our research sample. This exercise is important as it allows a greater familiarity with the use of this auxiliary tool of qualitative research.

Keywords: NVivo. Qualitative research. Data analysis. Social construction.

\section{INTRODUÇÃO}

960 presente artigo foi escrito originalmente para a disciplina de Metodologias Informacionais, no âmbito do Programa de Pós-Graduação em Sociologia, da Universidade Federal do Rio Grande do Sul (PPGS/UFRGS). A referida disciplina foi ministrada pelo professor Alex Niche Teixeira, no segundo semestre de 2012.

97 Graduada em Ciências Sociais pela Universidade Federal de Santa Maria (UFSM). Mestranda do Programa de Pós-Graduação em Sociologia, da Universidade Federal do Rio Grande do Sul (PPGS/UFRGS). E-mail: valesca.ames@gmail.com. 
As ferramentas informacionais de análise qualitativa, que podem ser definidas pelo uso do termo CAQDAS (Computer-aided qualitative data analysis software), desenvolveram-se em meados da década de 1980, através do trabalho conjunto realizado por cientistas sociais e especialistas em computação, com o objetivo de auxiliar no trabalho de análise de dados não numéricos e não estruturados.

Estas ferramentas informacionais tendem a ser especialmente úteis quando possuímos uma pesquisa qualitativa com grande volume de dados a serem analisados, visto que permitem a organização do material, a codificação do mesmo através de categorias pensadas durante o desenvolvimento da pesquisa e a geração de cruzamento entre categorias. Essas possibilidades facilitam de forma significativa a análise do material de pesquisa.

Entre os aplicativos hoje (2013) disponíveis para os cientistas sociais com o objetivo de auxiliar na análise de dados qualitativos, o NVivo é um dos softwares mais utilizados no Brasil. O NVivo permite a análise do material resultante da aplicação de entrevistas semi-estruturadas ou em profundidade, história de vida, história oral e gravações de grupos focais, através da codificação, categorização, indexação e organização deste material (SANTOS, 2001).

A emergência destes programas computacionais configura uma mudança no processo de pesquisa sociológico, pois modificam funções cognitivas humanas, representando uma nova forma de "pensar, representar e vincular dados" (PUEBLA, 2003). A exposição das potencialidades e limites do uso destes programas constitui-se no objetivo do artigo que ora se inicia. Para alcançar este objetivo, apresentaremos as possibilidades de uso do NVivo em uma pesquisa exemplo.

As características, potencialidades e limites do uso do programa NVivo será apresentada, de uma forma geral, na primeira seção do artigo, através de uma revisão de literatura sobre o tema. Na segunda seção do artigo, iremos apresentar os recursos básicos do NVivo, que serão utilizados para a organização dos dados da nossa pesquisa exemplo. A pesquisa exemplo constitui-se de um 
estudo que busca compreender o processo de construção social do Aeromóvel em Porto Alegre, Rio Grande do Sul. A exposição dos objetivos, hipóteses e metodologia dessa pesquisa constitui a terceira seção do artigo. Por fim, na quarta seção, buscaremos visualizar a aplicação do software NVivo ao nosso exemplo, salientando suas contribuições na análise deste caso específico.

\section{POTENCIALIDADES E LIMITES DO USO DO PROGRAMA NVIVO}

De uma forma geral, o uso dos programas para análise de dados qualitativos apresentam potencialidades que se expressam através da possibilidade de registro de todo o processo de investigação; possibilidade de pesquisas múltiplas sobre o mesmo material; organização do material da pesquisa; "economia de tempo e de custos; possibilidade de explorar de forma acurada o relacionamento entre os dados e as vantagens em termos de uma estrutura formal que auxilia na construção conceitual e teórica dos dados" (TEIXEIRA; BECKER, 2001, p. 95).

Apesar dos benefícios acima descritos, ainda há debates sobre os riscos envolvidos com o uso dessas ferramentas de apoio à pesquisa. Algumas dificuldades referem-se ao possível distanciamento entre pesquisador e dados, ou seja, o distanciamento entre a experiência viva entre pesquisador e pesquisado e a transcrição e análise da entrevista, onde a geração de grandes bases de dados ou "nós" pode aparecer como o objetivo central da análise; tentação de reduzir os dados qualitativos a dados quantitativos, na falsa ilusão de que os segundos sejam mais "objetivos" do que os primeiros; possibilidade de perder o controle no processo de codificação, com o risco de o pesquisador tentar adequar sua metodologia às funcionalidades da ferramenta (LAGE, 2011).

Uma maneira de evitar esses problemas relacionados ao uso indevido dos programas de análise qualitativa é adotar uma postura de vigilância epistemológica, de constante crítica do trabalho sociológico, não esquecendo o 


\section{v. I. ก. 2. ดg०. 2013 - ARTIGOS}

processo de construção social e sociológico do dado observável, como salientado por Bourdieu, Chamboredon e Passeron (1999).

O sociólogo deve sempre ter em mente que a compreensão do significado dos textos depende de uma série de pressupostos teóricos que acompanham a pesquisa em todas as suas fases. Os conceitos e categorias que são geradas para a análise qualitativa de textos com o auxílio do programa NVivo dependem dos objetivos, hipóteses e desenho da pesquisa, portanto, dependem de uma escolha teórica por parte do investigador. Por este motivo, a análise dos dados não pode ser reduzida a alguma relação supostamente objetiva entre categorias e dados, mas depende de uma análise interpretativa criativa por parte do investigador.

O Nvivo, por si só, não analisa os dados, mas apenas auxilia esse processo, através de um ambiente onde torna-se possível "criar, gerenciar e explorar ideias e categorias, minimizando as rotinas de trabalho e maximizando a flexibilidade da análise, para descobrir novas ideias e desenvolvê-las" (SANTOS, 2001, p. 132). Este processo de criação e exploração de ideias e categorias pode ser realizado através da codificação dos textos e da exploração de ideias sobre as informações disponíveis.

Antes de ter início a codificação do material no NVivo, o pesquisador deve ter em mente quais são as perguntas que pretende responder através de sua pesquisa, quais são seus objetivos e hipóteses. Além disso, deve conhecer os recursos básicos do NVivo, e a maneira como eles podem ser utilizados. Quando tudo isto está bem delimitado, e quando o material de pesquisa (matérias de jornais, entrevistas transcritas, vídeos, fotos) está organizado, este pode ser importado para o programa, codificado e analisado. A seguir, apresentamos os principais recursos do NVivo, que serão utilizados na análise de nossa pesquisa exemplo.

\section{RECURSOS BÁSICOS DO NVIVO}


Entre as estruturas básicas que compõem o NVivo encontramos as "fontes", os "nós", e as "classificações". Estes recursos servem para inserir, organizar e classificar o nosso material de pesquisa. Quando estamos envolvidos mais diretamente com a análise do projeto, exploramos os seguintes recursos: "coleções" "consultas", "relatórios" e "modelos". Estes recursos servem para questionarmos os nossos dados, possibilitando a geração de matrizes, gráficos, modelos de análise e consultas a palavras-chave, por exemplo.

As fontes referem-se ao nosso material de pesquisa, que pode incluir documentos, PDFs, arquivos de áudio, vídeo e imagens. Este recurso serve para importarmos e organizarmos estes documentos e divide-se de três maneiras:

a) Fonte Interna: refere-se ao material central de pesquisa importado ou criado no software. Inclui documentos, vídeo, áudio e imagens;

b) Fonte Externa: diz respeito àqueles materiais que não podem ser importados, mas que são importantes para a realização da pesquisa. Inclui sites, apresentações power point, livros, artigos de jornais, etc.;

c) Memos: são resumos e reflexões que podem ser associadas às fontes ou aos nós.

Os nós servem para codificar o material da pesquisa, eles são "recipientes que armazenam a codificação, ou seja, os nós irão conter a referência a uma porção de texto codificado" (TEIXEIRA; BECKER, 2001, p. 97). Os nós podem referir-se a temas, pessoas, organizações, etc. As codificações são índices de referência adicionados a porções do texto, regiões de fotos, ou trechos de sons e imagens, ela envolve uma reflexão sobre o material analisado, através da criação de ideias e pensamentos a ele relacionados, que irão formar os nós. Um determinado documento, como uma entrevista, por exemplo, pode ser codificado em diferentes nós.

$\mathrm{Na}$ aba dos nós, encontramos a pasta denominada "relacionamentos". Nesta pasta é possível definirmos uma ligação (relação de sentido) entre dois itens (fonte, nós, conjunto) que encontram-se no projeto, relacionando-os, e assim, criando um novo nó. $O$ relacionamento armazena trechos do documento que 


\section{v. I. ก. 2. ดg०. 2013 - ARTIGOS}

indicam uma determinada relação entre, por exemplo, uma fonte e um nó. O tipo de relacionamento é definido pelo pesquisador nas classificações.

Através da aba "classificações" podemos trabalhar com dados estruturados em tabelas. As classificações dizem respeito a características ou atributos de determinada fonte, nó ou relacionamento. Assim, as entrevistas realizadas com uma determinada pessoa viram um nó (ou caso). Estas entrevistas, então, podem ser classificadas segundo alguns atributos como: idade, posição política, renda, etc. Assim, todas as falas de um entrevistado específico ficam marcadas por estes atributos.

$\mathrm{Na}$ aba denominada "coleções" é possível criarmos um conjunto para determinadas entrevistas, dado que a separação por pastas pode não ser útil quando se trata de formar uma classificação para as fontes, por exemplo. A formação do conjunto pode ser útil para procurar palavras em fontes variadas.

Por fim, a aba "consultas" auxilia a análise dos dados, através da construção de tabelas resultantes do cruzamento entre elementos do projeto, como nós e atributos, por exemplo. As consultas também permitem encontrar palavras ou nós específicos que estejamos procurando ou, ainda, aquelas palavras que aparecem com mais frequência no texto.

Depois de analisados os dados, os modelos, gráficos ou nós codificados podem ser exportados e utilizados para a composição do relatório final da pesquisa, que reúne em um texto os resultados alcançados pelo pesquisador através da exploração de seus dados.

\section{PESQUISA EXEMPLO - O PROCESSO DE CONSTRUÇÃO SOCIAL DO AEROMÓVEL EM PORTO ALEGRE/RS}

A pesquisa que utilizamos para exemplificar um possível uso da ferramenta NVivo ainda apresenta-se em forma de projeto de pesquisa. Apesar do caráter preliminar da análise, algumas funcionalidades básicas do NVivo podem 
ser visualizadas. Inicialmente, iremos apresentar os objetivos, hipóteses e metodologia da nossa pesquisa exemplo.

A pesquisa possui como objetivos:

a) Analisar o processo de construção social do Aeromóvel ${ }^{98}$ a partir da controvérsia política, econômica e técnica estabelecida em torno dele e os diferentes grupos sociais que se envolveram na controvérsia, portadores de distintos valores, crenças e interesses políticos, econômicos e técnicos;

b) Identificar os atores envolvidos na controvérsia e os discursos por eles mobilizados em defesa ou contra a implantação do Aeromóvel;

c) Identificar e detalhar os contextos históricos, econômicos e culturais encontrados no desenvolvimento do referido artefato, identificando sua contribuição para a emergência da controvérsia.

A pesquisa partirá da hipótese de que a implantação e uso de uma tecnologia, no caso, o Aeromóvel, relaciona-se a dimensões sociais imbricadas em seu desenvolvimento. A dimensão social diz respeito a crenças, valores e interesses existentes em âmbitos sociais, políticos e econômicos, que dão origem a controvérsias entre diferentes grupos sociais. O processo controverso estabilizase e culmina com a aceitação ou não da tecnologia por parte da sociedade ${ }^{99}$.

Dado que o objetivo da pesquisa consiste em compreender o processo de construção social do Aeromóvel, os procedimentos metodológicos buscarão reconstruir e compreender a maneira pela qual a tecnologia foi interpretada por

98 O Aeromóvel é um projeto tecnológico de transporte urbano concebido no final da década de 1960 pelo técnico em aeronáutica Oskar Coester. Caracteriza-se por um sistema que utiliza propulsão pneumática (baseada no barco à vela), redução de peso morto e sistema rodatrilho. No sistema Aeromóvel o ar é soprado por ventiladores - de acionamento elétrico através de um duto localizado dentro da via elevada, o vento empurra uma aleta e o trem se movimenta sobre rodas de aço. O projeto, desde a década de 1970, passou por várias tentativas de implantação, especialmente ao longo da década de 1980, porém sem sucesso. A inauguração desse projeto está prevista para o ano de 2013, em Porto Alegre, Rio Grande do Sul, ligando a estação Aeroporto Salgado Filho ao trem metropolitano.

99 A hipótese, objetivo e metodologia da pesquisa exemplo possui como base teórica a abordagem da Construção Social da Tecnologia, da qual Trevor Pinch e Wiebe Bijker são os principais representantes. Essa abordagem aponta o caráter construído dos artefatos tecnológicos, na medida em que o processo de construção e desenvolvimento destes são condicionados por fatores de ordem social, política, econômica, histórica e cultural (PINCH; BIJKER, 1987). 
diferentes grupos sociais e como essas interpretações, que deram origem a controvérsias entre os grupos, interferiram no projeto de implantação do Aeromóvel.

O método de pesquisa será o estudo de caso do processo que se caracteriza por tentativas de implantação do Aeromóvel em Porto Alegre, iniciado no final da década de 1970 e que se estende até o ano de 2013.

A primeira etapa da pesquisa será documental, consistindo na busca de registros na mídia impressa de Porto Alegre (jornal Zero Hora) desde a década de 1970, em que começaram os primeiros testes com o Aeromóvel. A segunda etapa da pesquisa será uma análise dos contextos sociais, históricos, econômicos e políticos vinculados aos momentos controversos de desenvolvimento do Aeromóvel. Por fim, a última etapa da pesquisa consistirá na realização de entrevistas narrativas com pessoas que compõem os grupos sociais relevantes e análise dos relatórios técnicos produzidos por cientistas e engenheiros que se envolveram no projeto Aeromóvel.

A primeira e segunda etapa da pesquisa permitirá delimitar os grupos sociais relevantes, a partir dos quais selecionaremos aqueles membros que se envolveram mais diretamente com a construção do Aeromóvel e que, por este motivo, serão nossos entrevistados. Na etapa da realização das entrevistas, atentaremos para os problemas ou vantagens que cada grupo social enxerga com relação ao artefato, onde interpretações diferentes, relacionadas aos diferentes grupos sociais, poderão ser identificadas.

Além das entrevistas, também serão analisados os relatórios técnicos referentes ao projeto do Aeromóvel, formulados pela FUNDATEC/UFRGS (Fundação Universidade-Empresa de Tecnologia e Ciências da Universidade Federal do Rio Grande do Sul) e pelo IPT (Instituto de Pesquisas Tecnológicas), e que foram também alvo de interpretações diferentes por parte de diferentes cientistas e engenheiros.

Após a transcrição das entrevistas, a seleção das matérias de jornais, bem como de projetos que objetivaram analisar a viabilidade técnica e econômica do 
Aeromóvel, o material será analisado por meio de uma análise de discurso, que será realizada com a ajuda do programa de análise qualitativa NVivo.

\section{ETAPAS DE ORGANIZAÇÃO E ANÁLISE DE DADOS COM O NVIVO}

No caso da pesquisa que aqui utilizamos como exemplo, os dados serão organizados em três etapas, conforme apresentado no quadro 1.

Quadro 1 - Etapa De Tratamento Dos Dados Da Pesquisa No Ambiente Do Nvivo

\begin{tabular}{|c|c|c|}
\hline $\begin{array}{c}\text { Estruturação do projeto } \\
\text { no ambiente NVivo }\end{array}$ & $\begin{array}{c}\text { Codificação e análise dos } \\
\text { dados }\end{array}$ & $\begin{array}{c}\text { Resultados da pesquisa } \\
\text { projeto no NVivo }\end{array}$ \\
\hline $\begin{array}{c}\text { Cadastramento do } \\
\text { entrevistas e relatórios } \\
\text { técnicos }\end{array}$ & $\begin{array}{c}\text { Geração de gráficos e } \\
\text { modelos }\end{array}$ \\
\hline $\begin{array}{c}\text { Importação e } \\
\text { classificação das fontes } \\
\text { de pesquisa }\end{array}$ & $\begin{array}{c}\text { Análise dos nós a partir } \\
\text { dos atributos dos } \\
\text { entrevistados }\end{array}$ & $\begin{array}{c}\text { Geração dos relatórios } \\
\text { com as informações } \\
\text { relacionadas ao processo } \\
\text { de análise dos dados }\end{array}$ \\
\hline Criação dos nós & & \\
\hline
\end{tabular}

FONTE: Adaptada de LAGE, 2011.

Inicialmente cria-se um cadastro do projeto no NVivo (no caso: O processo de construção social do Aeromóvel em Porto Alegre/RS). Após a criação do cadastro, o próximo passo é importar as fontes, ou seja, os documentos que serão analisados com a ajuda do NVivo. No caso da pesquisa exemplo, as fontes se constituem de entrevistas com membros dos grupos sociais relevantes, relatórios técnicos que buscaram analisar a viabilidade técnica e econômica do Aeromóvel e matérias do jornal Zero Hora.

Com a finalidade de organizar o material da pesquisa, as fontes podem ser classificadas (além da classificação em fontes internas, externas e memos) em 


\section{v. I. ก. 2. ดg०. 2013 - ARTIGOS}

subpastas, de acordo com o tipo de fonte. Por exemplo, cria-se uma pasta para as entrevistas, outra para os relatórios técnicos e uma terceira para as matérias de jornais.

Devido ao caráter preliminar da pesquisa exemplo, ainda em forma de projeto, na classificação "fonte interna" importamos o material referente a uma entrevista com o criador do Aeromóvel, Oskar Coester, realizada em outubro de 2012.

Após a importação das fontes, podemos partir para a criação dos nós, ou seja, a criação das categorias e conceitos que irão armazenar a codificação do material analisado. Esta etapa somente é possível depois de uma boa leitura do material e de uma reflexão sobre os objetivos da pesquisa.

As entrevistas individuais também podem ser organizadas na forma de nós. Assim, por exemplo, a entrevista realizada com Oskar Coester pode constituir um nó, também chamado de nó de caso. Desta maneira organizados, os nós podem ser classificados dentro de subpastas, como mostra a FIGURA 1. Posteriormente, a esses nós podem ser conferidos atributos, o que facilita a análise dos dados (o que será explicado no decorrer do artigo). Desta forma, as entrevistas ficam organizadas dentro da pasta denominada "entrevistados".

FIGURA 1 - Fragmento Da Subpasta "Entrevistados", Inserido Na Pasta "Nós"

\begin{tabular}{|c|c|c|c|c|c|c|c|}
\hline Nós & Procurar: & - Pesquisar em & r & Entrevistados & Localizar ag & Apagar & Busca avançada \\
\hline \multirow{9}{*}{$\begin{array}{l}\square \text { Nós } \\
\square \text { Entrevistados } \\
\square \text { Temas } \\
\text { Relacionamentos } \\
\text { Matrizes de nó }\end{array}$} & \multicolumn{7}{|l|}{ Entrevistados } \\
\hline & 1 Nome & & & Fontes & Referências & & Criado em \\
\hline & Ayrton Moraes Teixeira & & & 0 & 0 & & $26 / 10 / 201212: 34$ \\
\hline & Cloraldino Soares Severo & & & 0 & 0 & & $26 / 10 / 201212: 33$ \\
\hline & Guilherme Villela & & & 0 & 0 & & $26 / 10 / 201212: 33$ \\
\hline & Jorge Franciscone & & & 0 & 0 & & $26 / 10 / 201212: 32$ \\
\hline & José Augusto Amaral de Souza & & & 0 & 0 & & $26 / 10 / 201212: 33$ \\
\hline & Marco Antônio Damim & & & 0 & 0 & & $26 / 10 / 201212: 34$ \\
\hline & Oscar Coester & & & 1 & 1 & & $26 / 10 / 201212: 53$ \\
\hline
\end{tabular}

FONTE: Ames, 2013.

Uma segunda pasta na aba nós, como pode ser visualizado na FIGURA 2, diz respeito àquilo que denominamos "temas". Os "temas" compreendem nós que 
se referem a características das falas dos nossos entrevistados, que depois servirão como base para a codificação das entrevistas realizadas.

Os nós que compõem a pasta "temas" foram elaborados a partir do objetivo da pesquisa, que consiste em analisar como as controvérsias entre diferentes grupos sociais influenciaram o processo de construção do Aeromóvel. Essas controvérsias dizem respeito a diferentes interpretações sobre o que é o Aeromóvel (pois a definição sobre o que é a tecnologia difere de acordo com diferentes grupos sociais); sobre quais as expectativas com relação ao Aeromóvel (se é uma boa alternativa a outros meios de transporte urbano); quais as vantagens e desvantagens relacionadas ao artefato; quais os problemas que ele apresenta e, finalmente, quais as causas que teriam adiado a implantação desta tecnologia.

FIGURA 2- Lista De Nós De Temas, Que Se Encontram Na Subpasta "Temas".

\begin{tabular}{|c|c|c|c|c|c|c|}
\hline Nós & Procurar: & Pesquisar em & 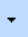 & Temas & Localizar ag & Busca avançada \\
\hline \multirow{2}{*}{$\begin{array}{l}\square \square \text { Nós } \\
\square \text { Entrevistados } \\
\square \text { Temas }\end{array}$} & \multicolumn{6}{|l|}{ Temas } \\
\hline & 1. Nome & & & A Fontes & Referências & Criado em \\
\hline (3) Relacionamentos & Aspectos jurídicos & & & 1 & 2 & $26 / 10 / 201215: 21$ \\
\hline \multirow{15}{*}{ Matrizes de nó } & aspectos politios & & & 1 & 3 & $26 / 10 / 201215: 44$ \\
\hline & aspectos tecnicos do aeromovel & & & 1 & 4 & $26 / 10 / 201215: 41$ \\
\hline & Autoridade cientifica & & & 1 & 1 & $26 / 10 / 201215: 24$ \\
\hline & controversias & & & 1 & 1 & $26 / 10 / 201215: 39$ \\
\hline & Costumes & & & 1 & 7 & $26 / 10 / 201212: 42$ \\
\hline & Crenças & & & 1 & 7 & $26 / 10 / 201212: 46$ \\
\hline & crenças, interesses científicos & & & 1 & 3 & $26 / 10 / 201215: 35$ \\
\hline & desconhecimento & & & 1 & 6 & $26 / 10 / 201215: 48$ \\
\hline & divergencias interpretativas & & & 1 & 2 & $26 / 10 / 201216: 17$ \\
\hline & ecologicamente mais correto & & & 1 & 1 & $26 / 10 / 201216: 23$ \\
\hline & eficiencia tecnica & & & 1 & 12 & $26 / 10 / 201212: 36$ \\
\hline & ineficiencia técnica & & & 1 & 3 & $26 / 10 / 201212: 38$ \\
\hline & influencia da mídia & & & 1 & 8 & $26 / 10 / 201212: 40$ \\
\hline & interesses economicos & & & 1 & 6 & $26 / 10 / 201212: 45$ \\
\hline & interesses políticos & & & 1 & 4 & $26 / 10 / 201212: 45$ \\
\hline Fontes & 5 inviabilidade economica & & & 1 & 1 & $26 / 10 / 201215: 33$ \\
\hline
\end{tabular}

FONTE: Ames, 2013.

Essas questões permitirão visualizar quais os argumentos utilizados pelos entrevistados para tentar demonstrar as vantagens $\mathrm{e}$ as desvantagens relacionadas ao Aeromóvel, quais as expectativas com relação ao projeto, quais 
os problemas relacionados com a tecnologia, quais as causas da postergação da implantação do artefato, e o que é o Aeromóvel ${ }^{100}$.

Assim, para cada uma dessas questões criamos um nó. As possíveis respostas a cada uma dessas discussões formarão subnós. Por exemplo: com relação a possível causa da postergação do projeto criamos os subnós: crenças, ineficiência técnica, inviabilidade econômica, desconhecimento, etc. ${ }^{101}$.

Após a importação das fontes e criação dos nós, podemos partir para a codificação do material da pesquisa. A codificação consiste em uma leitura minuciosa dos documentos da pesquisa com a finalidade de localizar passagens e Ihes atribuir significados correspondentes aos nós. Por exemplo, as referências às falas das pessoas que atribuem a causa da postergação da implantação do Aeromóvel ao desconhecimento do projeto por parte da população ficam codificadas no nó desconhecimento.

Durante 0 processo de codificação, podemos abrir os nós para observarmos todas as passagens que nele foram codificadas. Junto com estes fragmentos de textos, é apresentado um link para o documento original. Ao clicarmos no link podemos acessar o contexto do documento onde o trecho foi codificado. A FIGURA 3 ilustra o que estamos dizendo, e refere-se ao nó desconhecimento.

Nós também podem ser criados na fase de codificação, na medida em que o pesquisador considerar conveniente criá-los. "O processo de codificação em geral é executado até que o pesquisador entenda que não há mais o que codificar nas fontes de dados do projeto" (LAGE, 2011, p.210). O pesquisador deve estar atento ao momento de parar com a codificação, pois pode correr o risco de codificar além do necessário para responder ao problema de pesquisa.

Com os recursos do NVivo também é possível codificarmos todas as respostas a uma determinada pergunta e posteriormente compararmos as

100 As palavras em itálico referem-se a alguns dos nós que servirão como base para a codificação do material da pesquisa.

101 Como pode ser visualizado na figura 3, os nós ainda não estão classificados hierarquicamente, o que será elaborado assim que tivermos todo o material da pesquisa importado e adequadamente lido e analisado. 
respostas dos nossos entrevistados. Por exemplo: podemos codificar todas as respostas à pergunta referente às causas da postergação da implantação do Aeromóvel e posteriormente analisar as respostas de acordo com diferentes atributos dos respondentes.

FIGURA 3 - Trechos Da Entrevista Realizada Com Coester Codificados No Nó Desconhecimento

$<$ Internos \IEntrevistal|Transcricão Coester $0510>-\S 6$ referências codificadas [1,27\% Cobertura]

Referência 1 - 0,30\% Cobertura

Mas isso aí te da uma ideia do que tu ta pesquisando. Aquele pessoal não tava falando aquilo por interesse econômico, cultural ou coisa parecida, mas por puro desconhecimento.

Referência 2 - 0,17\% Cobertura

Mas esse aqui é o pulo do gato, mas é uma coisa tão simples, tão idiota, que as pessoas não enxergam.

Referência 3 - 0,11\% Cobertura

Então esse detalhezinho, que é uma idiotize, eles não entendiam.

Referência 6 - 0,39\% Cobertura

É fundamentalmente eu acho que isso tudo é guiado pela... Tem três fatores que são fundamentais pra mim, primeiro era a ignorância, não sabem do que a gente ta falando, porque é um conjunto de coisas que eu te expliquei aqui que.

FONTE: Ames, 2013.

A codificação também pode ser facilitada através do uso da aba "consultas", visto que essa permite a codificação automática das fontes com base em palavras ou frases que elas contenham (TUTORIAL NVIVO 9.2, 2011). Por exemplo, podemos procurar pela palavra costumes e codificar automaticamente todas as passagens em que ela aparece.

Após a codificação dos documentos da pesquisa, podemos passar para a fase de análise dos dados. Essa fase pode ser facilitada através do uso dos recursos disponíveis nas abas "coleções", "consultas", "relatórios" e "modelos". 
A aba "consultas" pode auxiliar no teste de ideias, exploração de padrões e conexões entre temas, tópicos, pessoas e lugares (TUTORIAL NVIVO 9.2, 2011). Por exemplo, é possível visualizarmos as partes codificadas com determinadas palavras (vantagens e desvantagens, por exemplo), e explorar suas diferenças; agrupar passagens de nós classificados de acordo com certos atributos e questionar, por exemplo, o que os grupos de políticos pensam sobre as vantagens do Aeromóvel?

Através do uso dos recursos da aba consultas, é possível, também, executar uma consulta de frequência de palavras para observarmos aquelas que são mais constantes nas falas dos nossos entrevistados, ou para analisar qual o nó em que há maior ocorrência de uma determinada palavra. As passagens em que essas palavras aparecem podem então ser salvas em um nó para análise futura.

$\mathrm{Na}$ aba "classificações" é possível trabalharmos com dados estruturados em tabelas. Aqui, os casos específicos (Oskar, Jorge) ganham atributos. Assim, posso ter várias fontes para Oskar (várias entrevistas) e estas são classificadas segundo algumas de suas características. Por exemplo: posição em relação ao Aeromóvel (favorável ou contrário), grupo social do qual faz parte (políticos, empresários, engenheiros). Deste modo, essa instância encerrará todas as características referentes à entrevista de Oskar. Isso torna possível o cruzamento entre nós e atributos, a comparação entre falas de diferentes entrevistados segundo seus atributos particulares, etc. através do uso das consultas. Por exemplo, caso classifiquemos nossas fontes em um nó de acordo com o atributo grupo social, poderão ser feitas perguntas como: qual a posição mais frequente com relação ao Aeromóvel no grupo de políticos?

A classificação realizada de acordo com a pesquisa exemplo (no caso, com a entrevista realizada com Oskar Coester) pode ser visualizada na FIGURA 4.

Os resultados da pesquisa podem ser apresentados e visualizados sob a forma de gráficos ou modelos de informações. Estes recursos servem para 
visualizarmos conexões entre nós ou itens que estão conectados a uma determinada fonte ou nó.

Os modelos "podem ser gerados automaticamente pelo NVivo, a partir dos dados codificados e dos relacionamentos criados entre eles ou desenhados pelo pesquisador; ou, ainda, a partir de um misto de ambos" (LAGE, 2011, p. 212). Um modelo pode ser apresentado com formas, cores, tamanhos e cor de letras diferentes, e pode ser editado pelo pesquisador a qualquer momento do desenvolvimento da pesquisa no ambiente NVivo. No caso da pesquisa exemplo, podemos gerar um modelo para representar os principais problemas relacionados ao Aeromóvel, segundo os nossos entrevistados.

FIGURA 4 - Classificação Do Nó Oskar Coester, Segundo Alguns De Seus Atributos

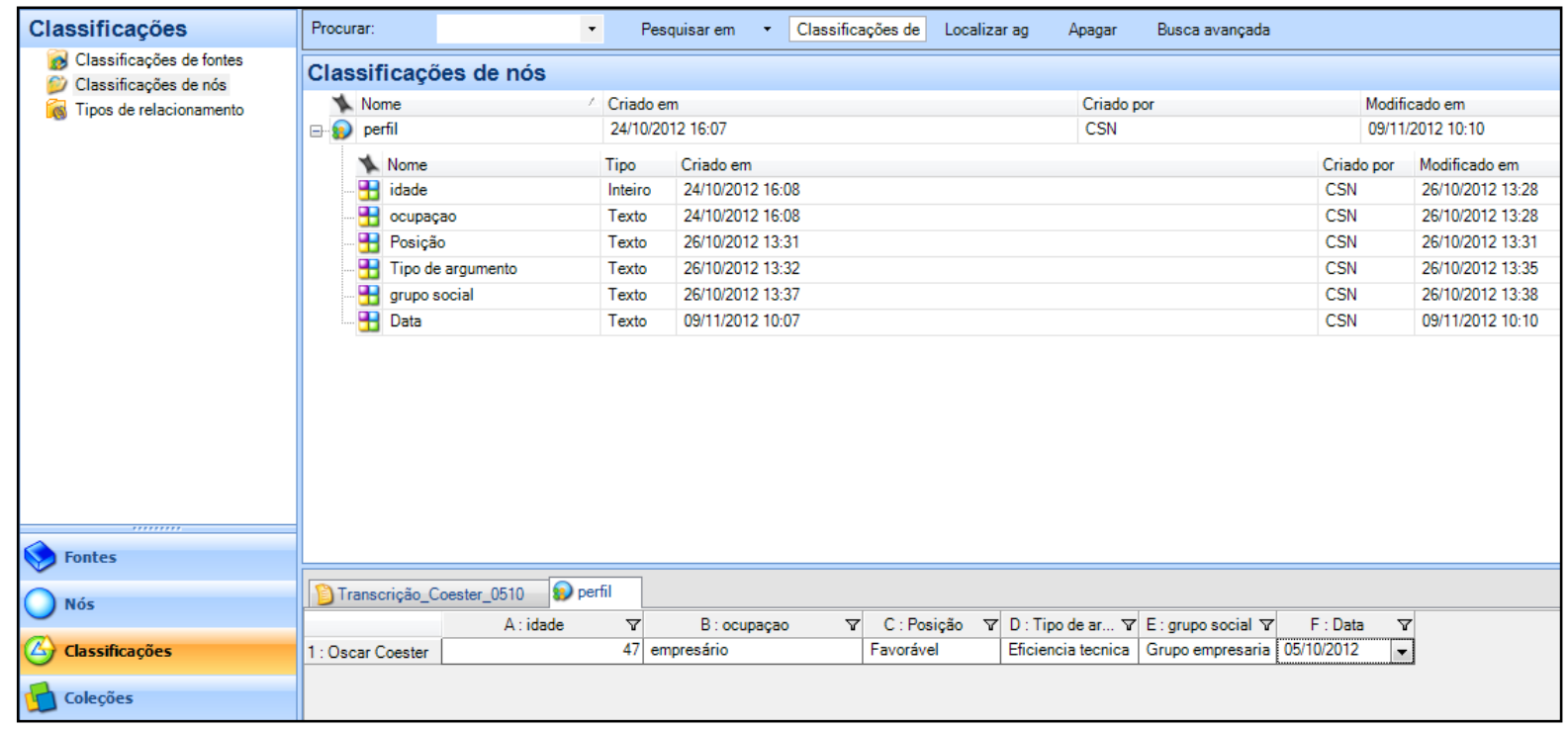

FONTE: Ames, 2013.

Os gráficos também podem ser formatados em cores, tamanhos e dimensões diferentes, permitindo realizar diferentes cruzamentos entre os dados. No caso da nossa pesquisa exemplo, o NVivo permitiria criar um gráfico para observarmos as diferentes atitudes dos grupos sociais com relação ao Aeromóvel, o que seria muito útil para aprofundar o entendimento a respeito do comportamento dos grupos sociais. 
O resultado final da análise de dados com o auxílio do NVivo é apresentado sob a forma de relatórios de pesquisa. Os relatórios gerados no interior do software podem ser exportados para outros aplicativos, como Excel ou Word, por exemplo. Na apresentação dos resultados nos relatórios podem ser utilizados os recursos gráficos do NVivo, mencionados anteriormente.

\section{CONSIDERAÇÕES FINAIS}

O objetivo central deste artigo foi apresentar as possibilidades de utilização do software NVivo, a partir de sua aplicação à pesquisa exemplo, que busca compreender o processo de construção social do Aeromóvel em Porto Alegre/RS. Também apresentamos as potencialidades e limites da utilização dessa ferramenta, salientando alguns cuidados que o pesquisador deve tomar quando utiliza esse programa auxiliar ao processo de análise de dados qualitativos.

Os dados que deverão compor a pesquisa que aqui nos serve como exemplo ainda não foram integralmente coletados, visto que a pesquisa ainda encontra-se em forma de projeto. Porém, foi possível apresentarmos quais recursos serão utilizados no desenvolvimento da pesquisa, e como eles poderão ajudar no processo de análise dos dados. Este exercício permite que o pesquisador reflita sobre o problema e os objetivos da pesquisa, formulando novas questões e dimensões que futuramente serão utilizadas.

Embora a análise aqui apresentada ainda seja muito prematura, e não apresente resultados em forma de gráficos ou modelos, é importante para que o pesquisador aprenda sobre algumas funcionalidades relacionadas ao uso do NVivo. Assim, quando todo o material da pesquisa for coletado, o aprendizado referente ao programa já está até certo ponto desenvolvido, evitando que a necessidade de aprender a usar o software torne-se um fator impeditivo da pesquisa com o auxílio do mesmo. 
Outro aspecto a ser considerado quando da utilização desse software de apoio relaciona-se à qualidade da pesquisa. Vale lembrar que a utilização dessa ferramenta por si só não aumenta nem diminui a qualidade da pesquisa, pois esta está relacionada à qualidade do relacionamento entre referencial teórico, objetivos e métodos de coleta de dados.

Além disso, o pesquisador deve adotar uma postura de vigilância epistemológica durante todas as fases da pesquisa, inclusive quando se está analisando os dados no ambiente NVivo. Essa atitude pode ser caracterizada como uma atitude de reflexão epistemológica sobre os próprios pressupostos dos métodos de pesquisa, visto que até mesmo o modo de utilização das técnicas relaciona-se a pressupostos teóricos do investigador (BOURDIEU; CHAMBOREDON; PASSERON, 1999).

O NVivo, seguindo essa consideração, constitui-se como uma plataforma de análise de dados a partir de categorias prévias formuladas pelo pesquisador, que as relaciona aos conceitos que utiliza para compreender a realidade. Como os conceitos irão diferir de acordo com diferentes concepções teóricas, os mesmos dados podem ser analisados de formas diferentes, o que demonstra que o programa não permite a produção de dados supostamente mais objetivos ou neutros, mas serve apenas para facilitar o trabalho de organização e análise de dados.

\section{REFERÊNCIAS}

BOURDIEU, Pierre, CHAMBOREDON, Jean Claude; PASSERON, Jean Claude. Ofício de Sociólogo. Metodologia da pesquisa na sociologia. Petrópolis, Rio de Janeiro, 1999.

LAGE, Maria. Utilização do software NVivo em pesquisa qualitativa: uma experiência em EaD. Educação Temática Digital, Campinas, v. 12, n.esp., p. 198-226, mar. 2011.

PINCH, Trevor; BIJKER, Wiebe. The Social Construction of Facts and Artifacts: Or How the Sociology of Science and the Sociology of Technology Might Benefit Each 
Other. In: BIJKER, W.; HUGHES, T.; PINCH, T. (Eds.). The Social Construction of Technological Systems. Massachusetts: MIT Press, p. 17-50, 1987.

PUEBLA, César. Analisis cualitativo asistido por computadora. Sociologias, Porto Alegre, ano 5, n. 9, p. 288-313, jan/jun, 2003.

QSR INTERNACIONAL. Tutorial NVivo 9.2. 2011.

SANTOS, José Vicente. As possibilidades das Metodologias Informacionais nas práticas sociológicas: por um novo padrão de trabalho para os sociólogos do Século XXI. Sociologias, Porto Alegre, ano 3, n. 5, p. 116-148, jan/jun 2001.

TEIXEIRA, Alex. BECKER, Fernando. Novas possibilidades da pesquisa qualitativa via sistemas CAQDAS. Sociologias, Porto Alegre, ano 3, n. 5, p. 94113, jan/jun 2001. 